\title{
Imaging nuclei of MDA-MB-231 breast cancer cells by chiral ruthenium(II) complex coordinated by 2-(4-phenyacetylenephenyl)-1 $H$-imidazo[4,5 $][1,10] \mathrm{ph}$ enanthroline
}

Zhi-Ping Zeng, ${ }^{\dagger, \#}$ Qiong Wu, ${ }^{\dagger, \#}$ Fen-Yong Sun, ${ }^{\text {t,* }}$ Kang-Di Zheng, ${ }^{\S}$ Wen-Jie $\mathrm{Mei}^{\dagger{ }^{\dagger} *}$

'School of Pharmacy, Guangdong Pharmaceutical University, 280 Waihuan Road, 510006 Guangzhou, PRC

${ }^{*}$ Department of Clinical laboratory medicine, Shanghai Tenth People's Hospital of Tongji University, 301 Yanchang Road, 200072 Shanghai, PRC

${ }^{\S}$ College of traditional Chinese medicine, Guangdong Pharmaceutical University, 280 Waihuan Road, 510006 Guangzhou, PRC

*Correspondence: wenjiemei@126.com, sunfenyong@,263.net. 


\section{The ESI-MS spectra of $\Lambda / \Delta-R M 0627$}

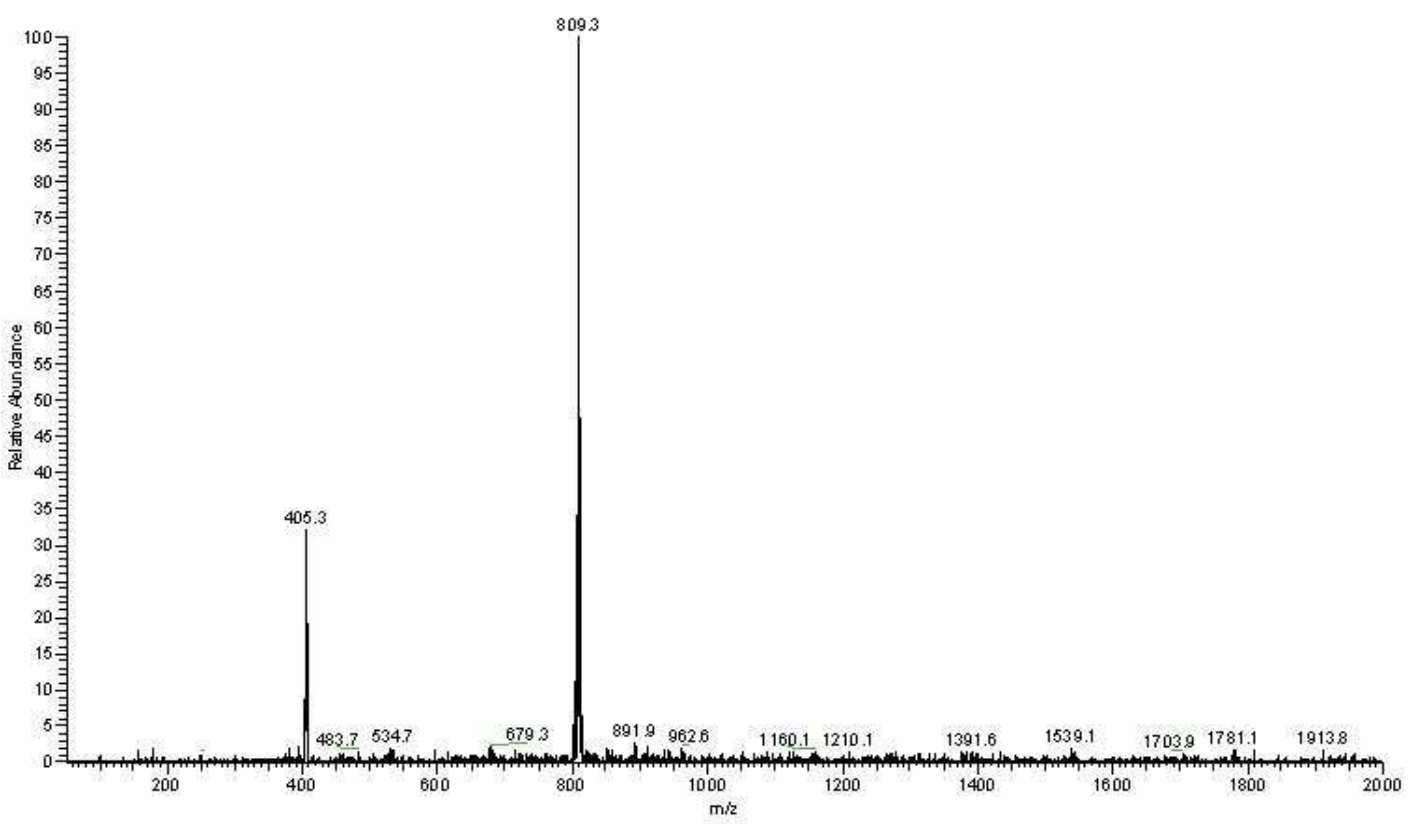

A

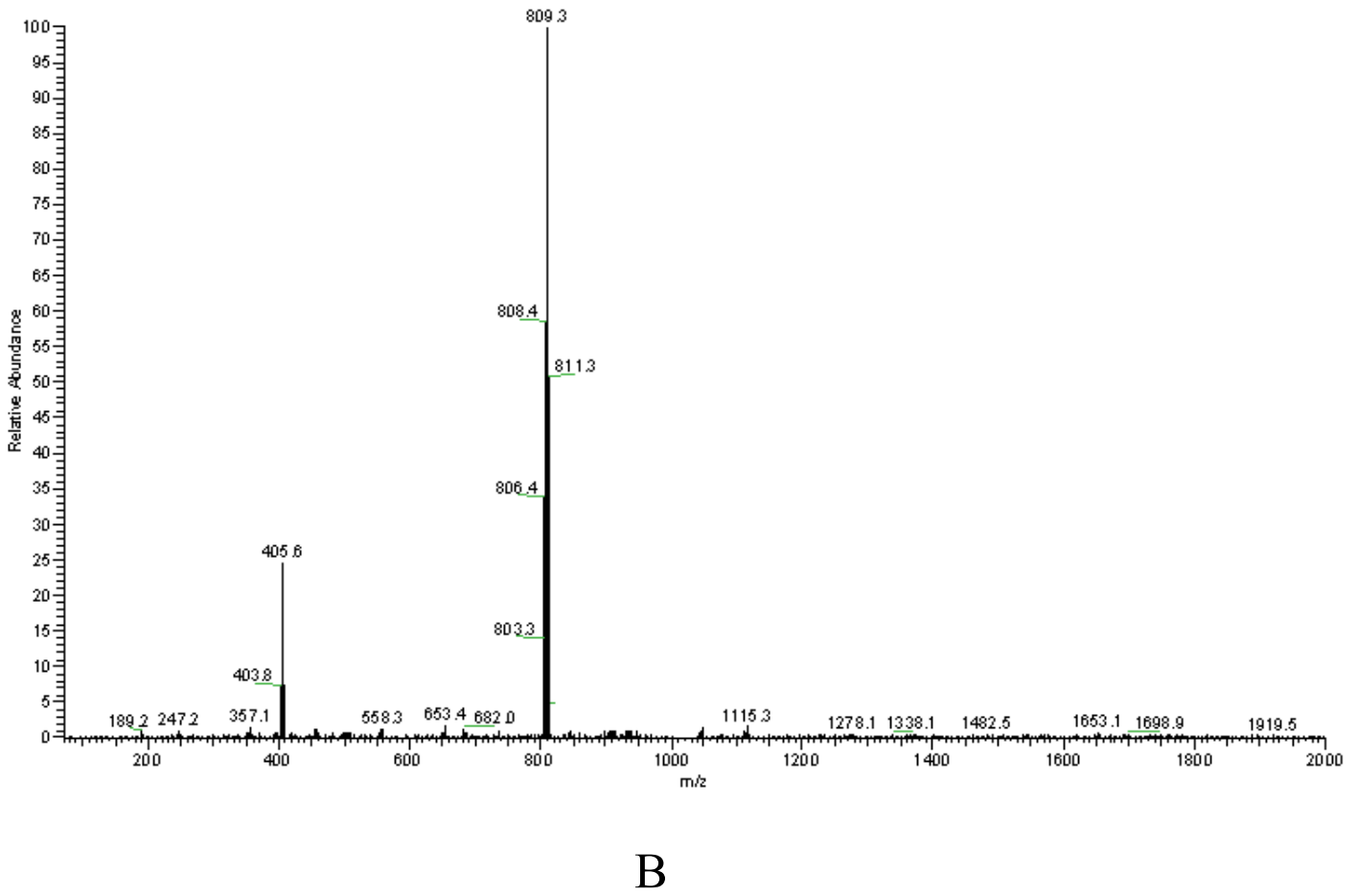

Figure S1. The ESI-MS spectra of chiral ruthenium(II) complexes $\Lambda$-RM0627 (A) and $\Delta$-RM0627 (B) 


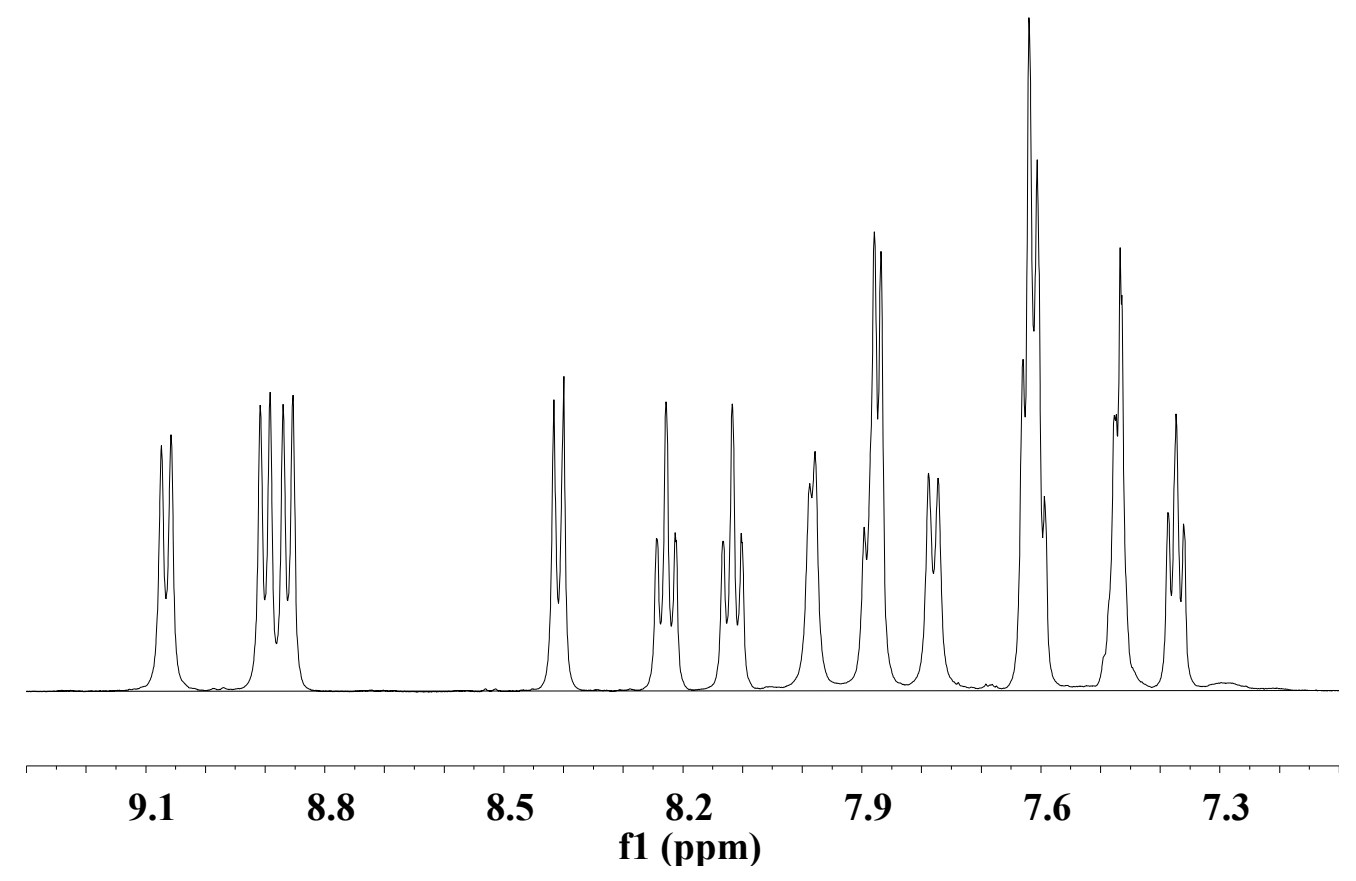

A

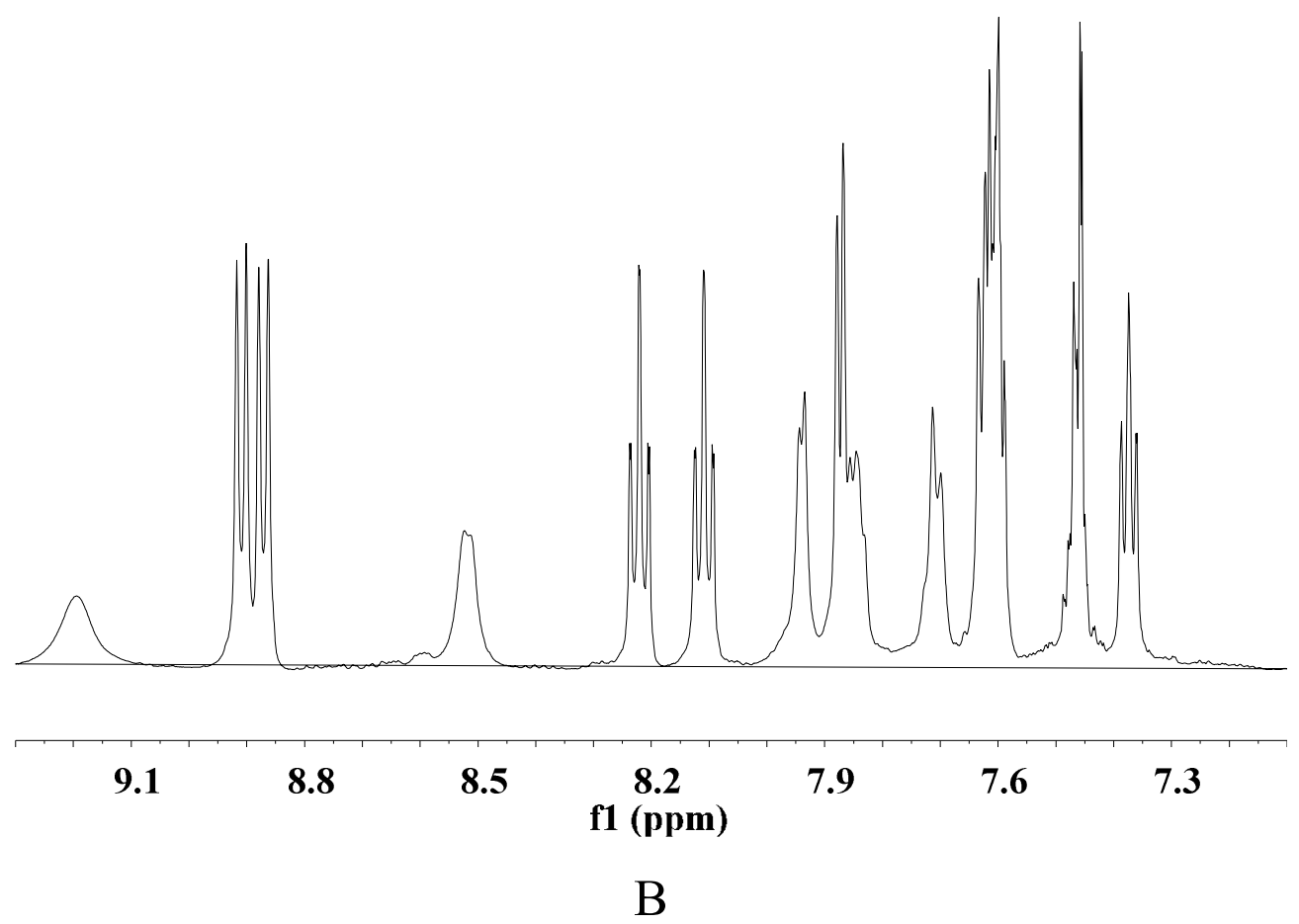

Figure S2. The ${ }^{1} \mathrm{H}$ NMR spectra of chiral ruthenium(II) complexes 4 -RM0627 (A) and 4 -RM0627 (B) 


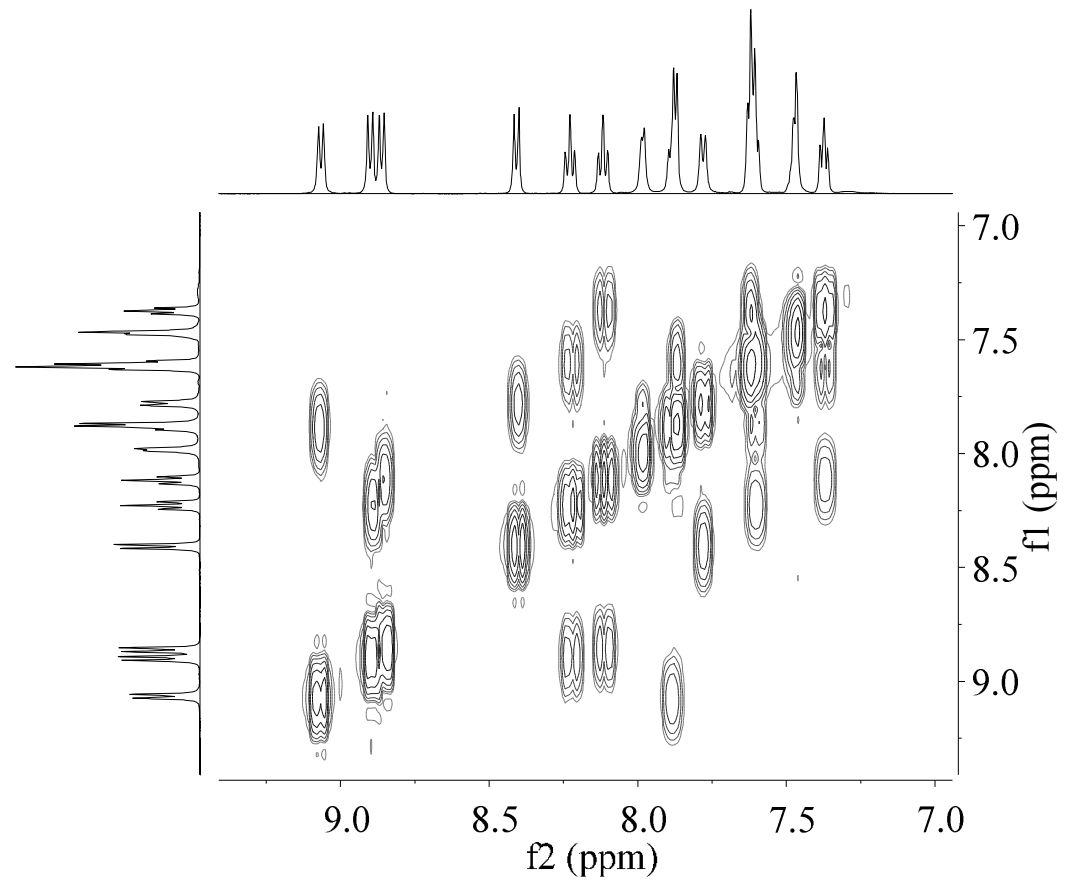

A

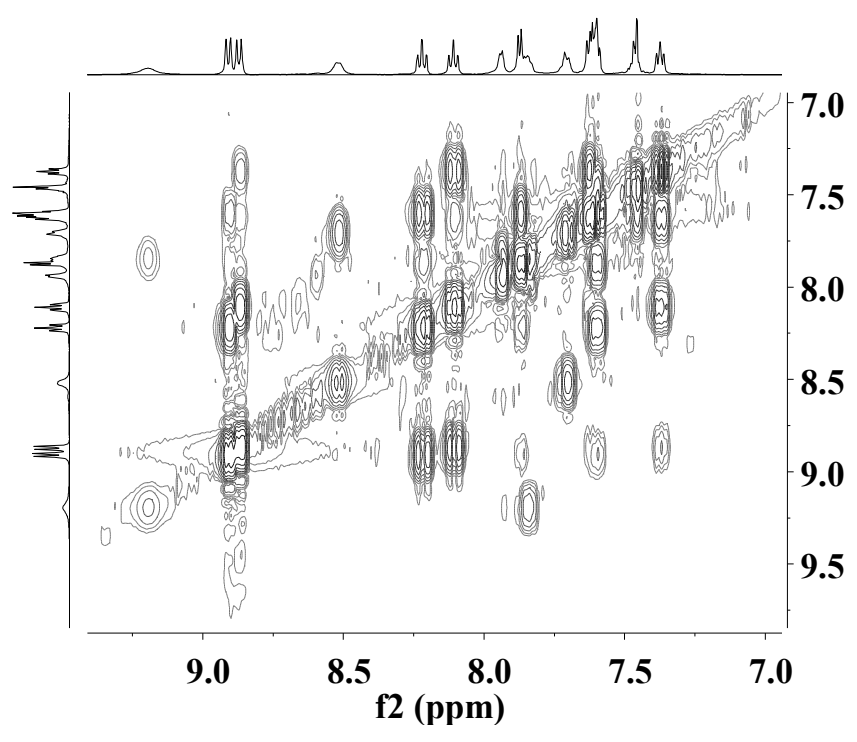

B

Figure S3. The ${ }^{1} \mathrm{H}{ }^{1} \mathrm{H}$ COSY spectra of chiral ruthenium(II) complexes $\Lambda$-RM0627

(A) and $\Delta$-RM0627 (B) 


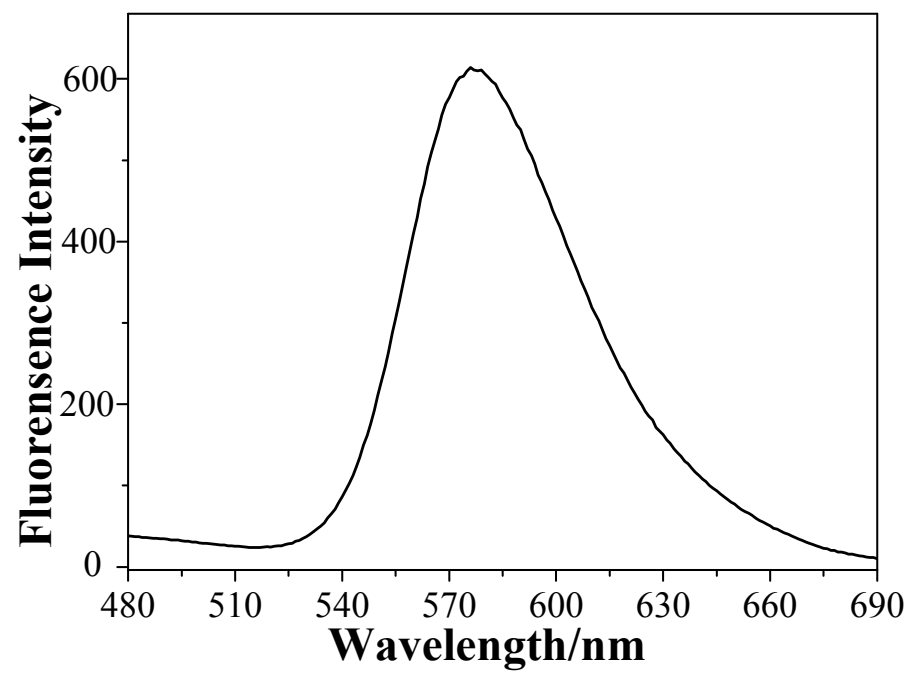

A

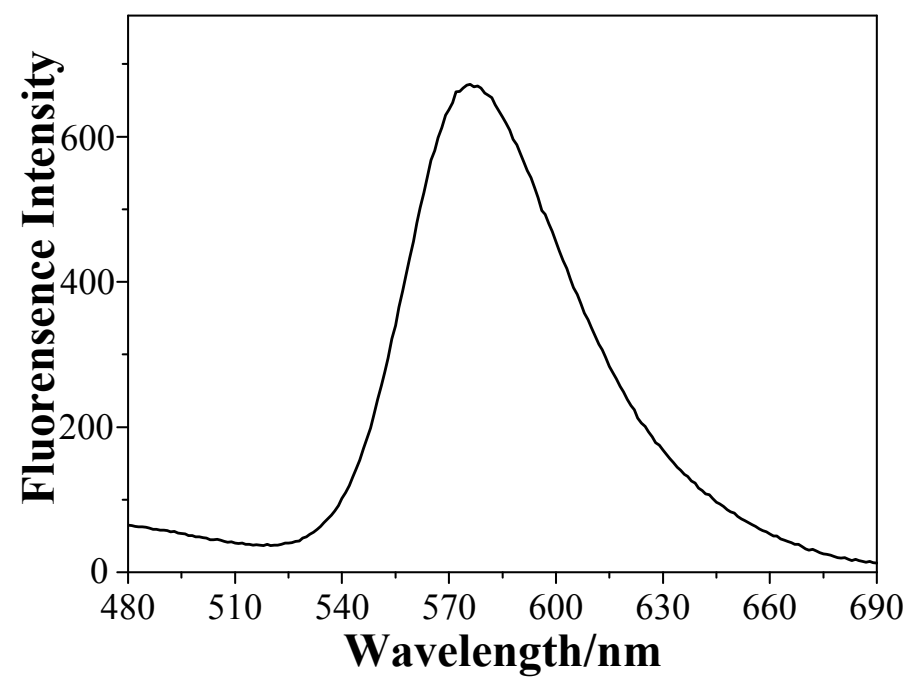

B

Figure S4. The fluorescence spectra of chiral ruthenium(II) complexes $\Lambda$-RM0627 (A) and $\Delta-\mathrm{RM} 0627$ (B). [Ru] $=20 \mu \mathrm{M}$, Excited at $350 \mathrm{~nm}$. 


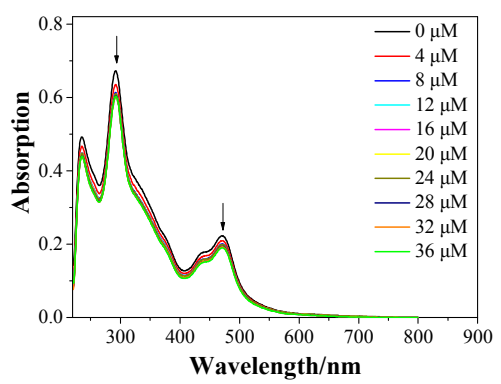

A

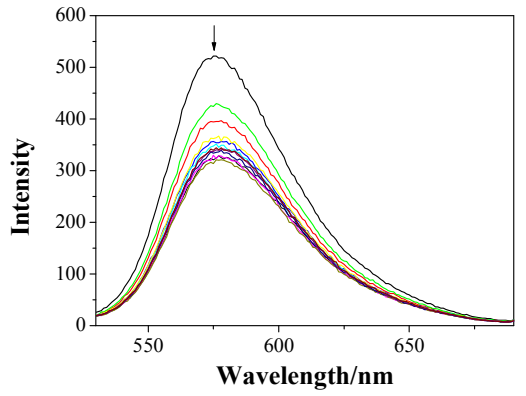

$\mathrm{C}$

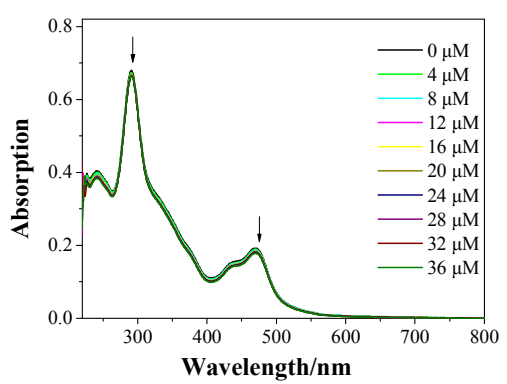

B

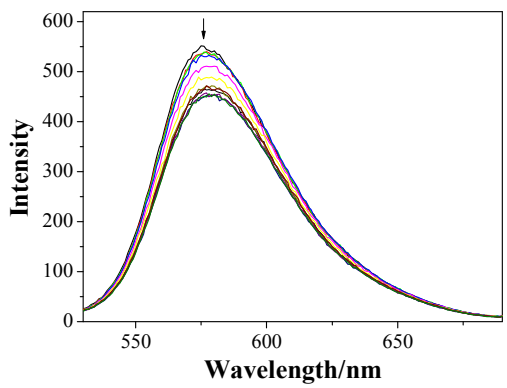

$\mathrm{D}$

Figure S5. The DNA-binding ability of a pair of chiral ruthenium (II) complexes. The absorption spectra of $\Lambda$-RM0627 (A) and $\Delta$-RM0627 (B) in the absence and presence of the CT-DNA. $([\mathrm{Ru}]=20 \mu \mathrm{M},[\mathrm{DNA}]=0.67 \mathrm{n} \mu \mathrm{M} ; \mathrm{n}=0,1,2$, etc. $)$ The fluorescence spectra of $\Lambda$-RM0627 (C) and $\Delta$-RM0627 (D) in the absence and presence of the CT-DNA. $([\mathrm{Ru}]=20 \mu \mathrm{M},[\mathrm{DNA}]=0.67 \mathrm{n} \mu \mathrm{M} ; \mathrm{n}=0,1,2$, etc. $)$

DAPI

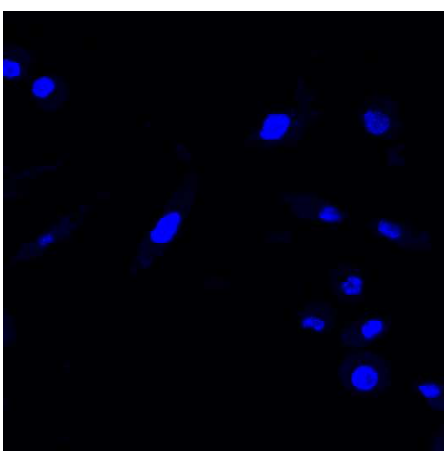

Racemic $\mathrm{Ru}(\mathrm{II})$
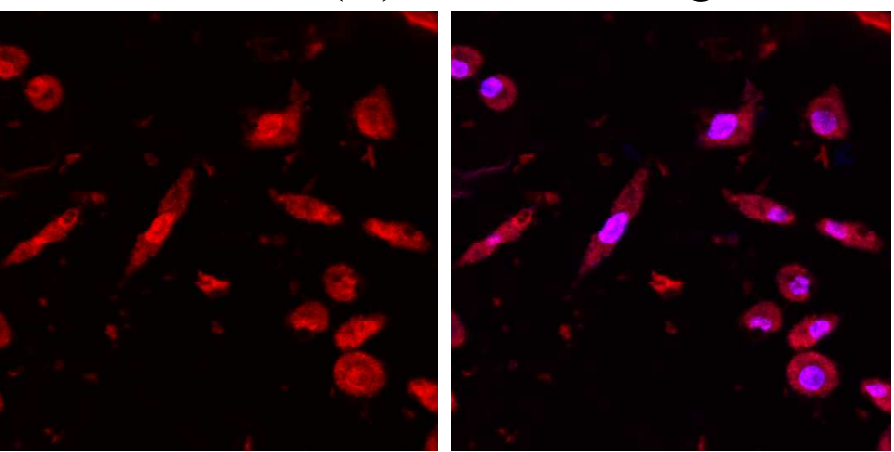

Figure S6. The co-localization of Racemic $\mathrm{Ru}(\mathrm{II})$ complex with DAPI. [Ru] $=20 \mu \mathrm{M}$; Excited at $350 \mathrm{~nm}$; Emission at 550 620 nm. 


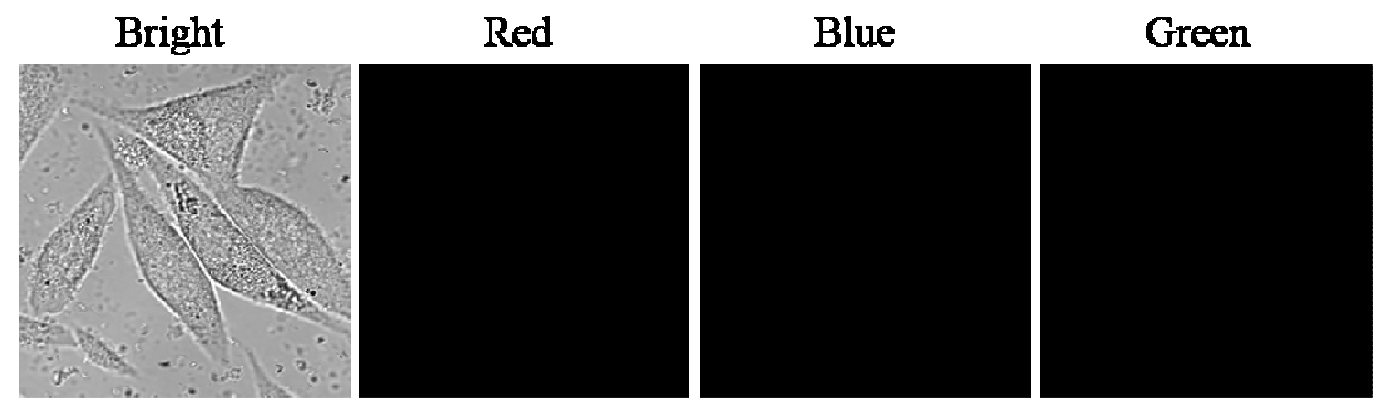

Figure S7. The negative control images of $\mathrm{HepG} 2$ cells without treatment with $\mathrm{Ru}$ complexes which is excited at $350 \mathrm{~nm}$ and emission for $550 \sim 620 \mathrm{~nm}$. 